\title{
Influence of screw density on thoracic kyphosis restoration in hypokyphotic adolescent idiopathic scoliosis
}

\author{
Ming Luo ${ }^{1 \dagger}$, Honghui Jiang ${ }^{2+}$, Wengang Wang ${ }^{1}$, Ning Li ${ }^{1}$, Mingkui Shen ${ }^{1}$, Peng Li ${ }^{1}$, Genzhong Xu ${ }^{1}$ and Lei Xia ${ }^{1 *}$ (D)
}

\begin{abstract}
Background: Previous studies have reported that rod composition and diameter, as well as the correction technique are key factors associated with thoracic kyphosis (TK) restoration. However, few study has analyzed the correlation between screw density and TK restoration in hypokyphotic adolescent idiopathic scoliosis (AIS).

Methods: Fifty-seven thoracic AIS patients with preoperative $T K<10^{\circ}$ treated with all pedicle screw fixation with a minimum 2-year follow-up were recruited. Preoperative and postoperative radiographic measurements, and information of posterior instrumentation were reviewed. Pearson and Spearman correlation coefficient analysis were used to assess relationships between change in TK and number of variables. Then, the included patients were classified into two groups (Group 1: postoperative $T K \geq 20^{\circ}$; Group 2: postoperative $T K<20^{\circ}$ ) to evaluate the influence factors of $T K$ restoration.

Results: The average preoperative TK was $4.75^{\circ}$, which was significantly restored to $17.30^{\circ}(P<0.001)$. Significant correlations were found between change in TK and flexibility of major thoracic curve $(r=0.357, P=0.006)$, preoperative TK $(r=-0.408, P=0.002)$, and screw density of concave side $(r=0.306, P=0.021)$, respectively. In the subgroup comparison, 17 patients (29.8\%) maintain the postoperative TK $\geq 20^{\circ}$, increased flexibility of major thoracic curve $(P<0.001)$, screw number of concave side $(P=0.029)$, and cobalt chromium rods $(P=0.041)$ were found in the group of postoperative $T K \geq 20^{\circ}$.

Conclusions: TK restoration remains a challenge for AIS patients with hypokyphosis, especially for the poor flexibility ones. Except for thicker and cobalt chromium rods, screw density of concave side might be another positive predictor of restoring normal kyphosis, which provides a stronger corrective force on the sagittal plane with more pedicle screws.
\end{abstract}

Keywords: Adolescent idiopathic scoliosis, Hypokyphosis, Thoracic kyphosis, Screw density

\section{Background}

Adolescent idiopathic scoliosis (AIS) is a tridimensional deformity afflicting millions of children who are at risk between the ages of 10-16 years. AIS has a prevalence of $2-4 \%$ in this population. The defined threshold for surgical treatment is when the major curve's Cobb angle is greater than $40^{\circ}$. Untreated AIS patients may have pulmonary limitations, back pain, and changes in appearance and overall motor function [1].

\footnotetext{
* Correspondence: xialeigu1@126.com

${ }^{\dagger}$ Equal contributors

${ }^{1}$ Institute of Spinal Deformity, the First Affiliated Hospital of Zhengzhou

University, Zhengzhou, Henan 450052, People's Republic of China

Full list of author information is available at the end of the article
}

Compared to the coronal correction, sagittal alignment restoration has received more attention [2-4]. Hypokyphosis, also called flat back, is one of the prominent features of AIS and has been defined as a sagittal curve (T5-T12) less than $10^{\circ}$, measured from the superior end-plate of the fifth thoracic vertebra to the inferior end-plate of the twelfth thoracic vertebra in the sagittal plane $[5,6]$. Hypokyphosis has an adverse impact on pulmonary function and lumbar disc degeneration [7-10]. In addition, preservation of thoracic kyphosis (TK) is critical to maintain sagittal balance in the surgical treatment of AIS $[2,11,12]$.

A Significant correlation between implant density and coronal correction has been previously observed in the 
surgical treatment of AIS [13-15]. However, few studies have evaluated the correlation between implant density and sagittal correction, and different conclusions were reported [16-18]. Larson et al. reported that increased implant density resulted in decreased TK in Lenke type 1 and 2 curves [16]. Conversely, Liu et al. demonstrated that high screw density on the concave side could provide better TK restoration [17]. Sudo et al. evaluated 36 AIS patients with preoperative TK with an angle less than $15^{\circ}$ and found that screw density was an independently predictive of change in TK [18].

Previous studies have reported that rod composition and diameter, as well as the correction technique are key factors associated with TK restoration [19-23]. To our limited knowledge, few study has analyzed the correlation between TK restoration and screw density in hypokyphotic AIS $\left(\mathrm{TK}<10^{\circ}\right)$. The purpose of the study is to evaluate the influence factors of TK restoration, especially for screw density, rod composition and diameter, which associated with all pedicle screw fixation.

\section{Methods}

\section{Patients identification}

After receiving approval from the institutional review board, the operative and radiological notes of consecutive AIS patients were retrospectively reviewed. The patients that were reviewed underwent spinal surgery from January 2009 to December 2014 at a single institution.

Selection criteria included the following: (1) Lenke type 1-4 AIS; (2) preoperative TK $(\mathrm{T} 5-\mathrm{T} 12)<10^{\circ}$; (3) one-stage posterior approach; (4) all pedicle screw construct, and (5) minimum 2-year follow-up. Exclusion criteria included the following: (1) Lenke type 5-6 AIS, early-onset scoliosis, or neuromuscular scoliosis; (2) hybrid instrumentation constituted with hooks or wires; (3) anterior-posterior approach; (4) pedicle subtraction osteotomy or vertebral column resection performed; and (5) reoperations related to the pedicle screw system.

\section{Surgical technique}

Two senior surgeons performed all the surgeries. After the standard posterior midline incision and the anatomical exposure of the spine, multilevel inferior facet resection and superior facet decortication were undergoing. After pedicle screws were implanted with a free hand technique, a metal rod was bended to the anticipated TK prior to insertion, and rod reduction, in order to turn the locking cap to reduce the rod into the screw head, were performed after the insertion of the concave rod. Simple rod rotation technique was applied for deformity correction. After insertion of the second rod and tightening of locking caps, distraction and compression were performed, and locking caps were finally tightened. Transverse connector was selectively used. The transverse processes and laminae were decorticated thoroughly, and allograft bone material was placed for fusion.

\section{Clinical and radiographic parameters}

Clinical measurements included the patients' age at surgery, gender, rod diameter, rod material, fused vertebral levels, and number of pedicle screws that were used. Screw density was defined as the number of pedicle screws per vertebrae that were implanted. Concave side screw density was calculated using the screw number of the concave side divided by the fused levels; convex side screw density was calculated in a same manner. Total screw density was calculated using the total screw number divided by the fused levels.

Standing posterior-anterior and lateral radiographs were measured for parameters before the surgery and at the last follow-up. Radiographic measurements included the patients' Lenke classification, Risser grade, apical vertebral rotation (Nash-Moe), Cobb angle of main thoracic (MT) curve, convex bending, TK (T5-T12), and lumbar lordosis (T12-S1). The flexibility index, MT correction rate, change in MT curve, and change in TK (postoperative TK - preoperative TK) were all calculated from above radiographic parameters.

\section{Statistical analyses}

In order to explore the correlation between change in TK and potential variables, including age, flexibility of MT curve, preoperative MT Cobb angle, preoperative TK, preoperative LL, fused levels, screw density of concave side, screw density of convex side, and total screw density, Pearson and Spearman correlation coefficient analysis were performed. According to the Lenke classification, the $\mathrm{N}$ of the sagittal modifier is from $10^{\circ}$ to $40^{\circ}$. However, many scholars hold the view that postoperation TK (T5-T12) less than $20^{\circ}$ is still hypokyphosis with, and it is generally agreed that operative treatment of thoracic idiopathic scoliosis should aim to improve TK to a degree more than $20^{\circ}[7,24]$. In order to evaluate the influence factors of a satisfied TK restoration, the cohort was then divided into two groups based on postoperative TK with the threshold of $20^{\circ}$. All data were collected and analyzed using IBM SPSS Statistics v.24.0 (IBM Corp., Armonk, N.Y., USA). $P<0.05$ was considered statistically significant.

\section{Results}

Fifty-seven consecutive thoracic AIS patients with hypokyphosis were carefully reviewed. There were 45 females and 12 males, and the average age at surgery was $14.39 \pm 1.82$ (range, 12-19) years old. According to the Lenke classification, [6] there were 28 type 1,16 type 2, 13 type 3 curves. Preoperative radiographs showed an average MT curve of $55.23^{\circ} \pm 11.65^{\circ}$ (range, $37^{\circ}-91^{\circ}$ ), and the average 
preoperative TK was $4.75^{\circ} \pm 3.45^{\circ}$ (range, $-4^{\circ}-9^{\circ}$ ). Postoperative MT significantly reduced to $15.74^{\circ} \pm 7.64^{\circ}$ (range, $2^{\circ}-35^{\circ}$ ), and postoperative TK was significantly restored to $17.30^{\circ} \pm 5.13^{\circ}$ (range, $7^{\circ}-30^{\circ}$ ).

In the correlation analysis between change in TK and variables, a linear trend was found between change in TK and flexibility of MT curve (Pearson: $r=0.357, P=0.006$; Spearman: $r_{\mathrm{s}}=0.384, P=0.003$. Figure 1$)$. A linear trend was also found between change in TK and preoperative TK (Pearson: $r=-0.408, P=0.002$; Spearman: $\mathrm{r}_{\mathrm{s}}=-0.445$, $P=0.001$. Figure 2). In addition, a positive correlation was found between change in TK and concave side screw density (Pearson: $r=0.306, P=0.021$; Spearman: $r_{\mathrm{s}}=0.290$, $P=0.029$. Figure 3 ). The correlation analysis between change in TK and variables are presented in Table 1.

In the subgroup analysis, the postoperative $\mathrm{TK} \geq 20^{\circ}$ group consisted of 17 patients (29.8\%; $5.5 \mathrm{~mm}$ Ti:6.0 mm Ti:5.5 mm CoCr:6.0 mm CoCr $=0: 7: 4: 6)$, whereas the postoperative TK $<20^{\circ}$ group had 40 patients $(70.2 \% ; 5.5 \mathrm{~mm}$ Ti:6.0 mm Ti:5.5 mm CoCr:6.0 mm CoCr = 5:23:10:2). No significant differences were found with respect to the following parameters: gender, age at surgery, Riser sign, apical vertebra rotation, convex-Bending Cobb angle, preoperative MT Cobb angle, postoperative MT Cobb angle, change in MT Cobb angle, MT curve correction, preoperative TK, preoperative LL, postoperative LL, change in LL, rod diameter $(5.5 \mathrm{~mm} / 6.0 \mathrm{~mm})$, fused levels, total screw number, screw number of convex side, total screw density, screw density of concave side, screw density of convex side. Except for significant differences in postoperative TK $(P<0.001)$ and change in TK $(P<0.001)$, poor flexibility of MT curve $(P<0.001)$, lower incidence rate of $\mathrm{CoCr}$ rod $(P=0.041)$, and smaller screw number of concave side $(P=0.029)$ were found in the postoperative TK $<20^{\circ}$ group. Interestingly, the MT curve correction (\%) in the postoperative $\mathrm{TK} \geq 20^{\circ}$ group was six percentage points lower than the other group, even though no significant difference was found ( $68 \pm 13$ vs $74 \pm 10, P=0.079)$. The clinical parameters are presented in Table 2 and the radiographic parameters are showed in Table 3.

\section{Discussion}

Increased attention should be allocated to TK restoration, as it remains a challenge for the surgical treatment of thoracic AIS patients. Decreases in TK after posterior spinal fusion using segmental pedicle screw construct has gained increased attention [2, 25, 26]. Although there is insufficient evidence demonstrating that hypokyphosis affects the clinical outcome in AIS patients, [27] directly or indirectly, influences on pulmonary function, $[8,9,28]$ adjacent-segment disease, [29] cervical sagittal alignment, [30] and lumbar lordosis have been found to be related to a decrease in TK after surgical treatment [31].

TK restoration is a continuing surgical challenge for AIS patients with hypokyphosis [21]. In our study, only 29.8\% hypokyphotic AIS achieved satisficed TK

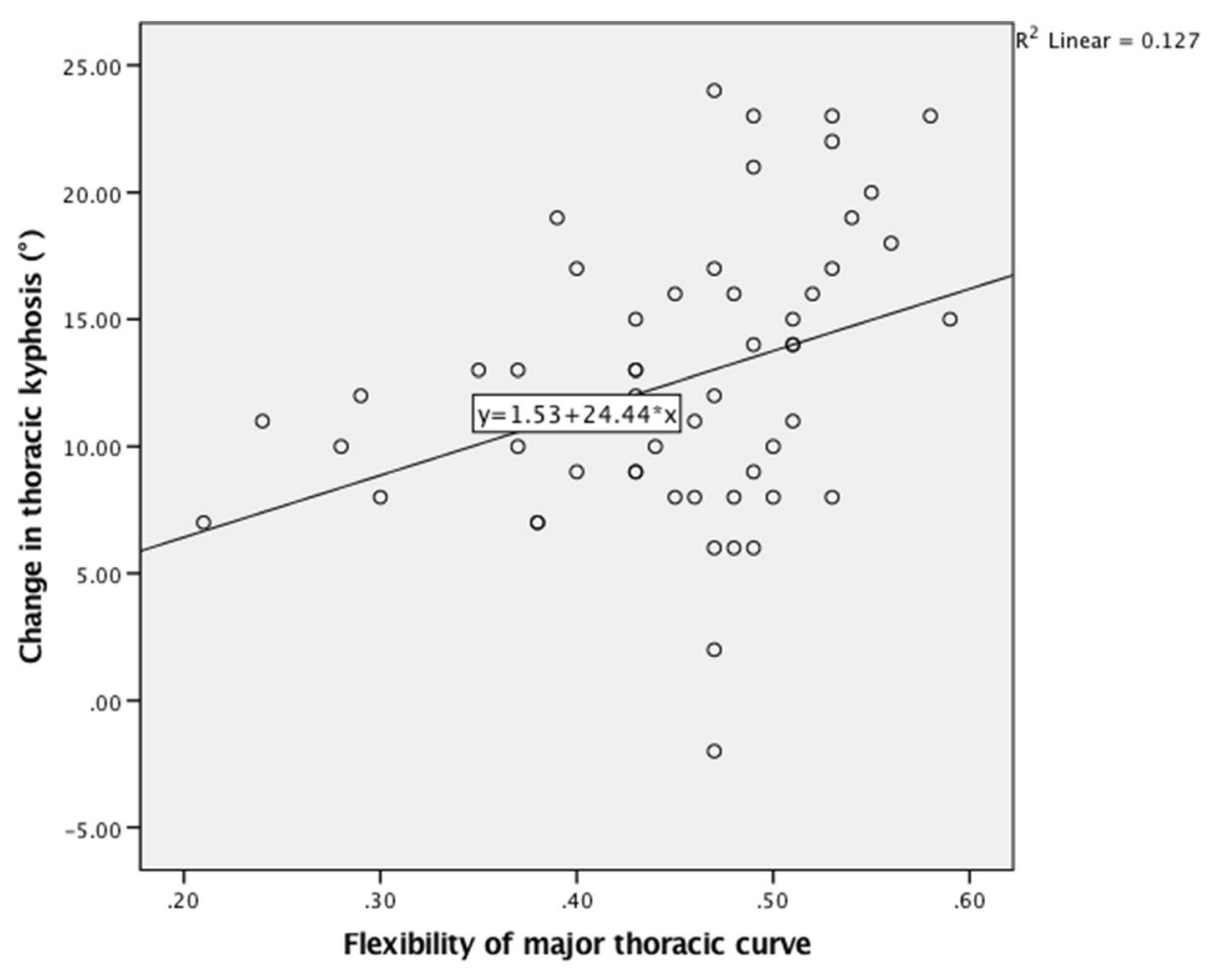

Fig. 1 Correlation between change in thoracic kyphosis and flexibility of MT curve 


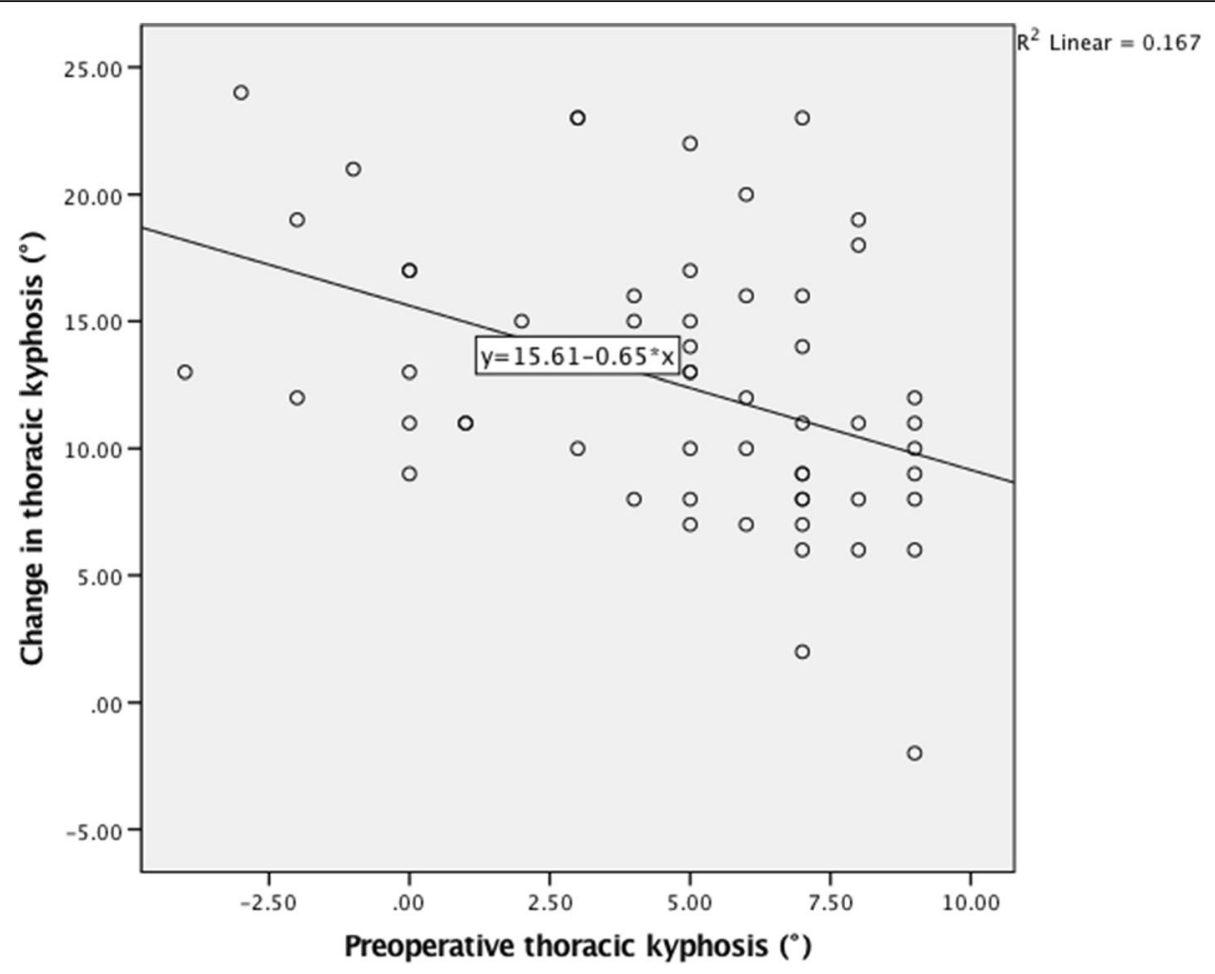

Fig. 2 Correlation between change in thoracic kyphosis and preoperative thoracic kyphosis

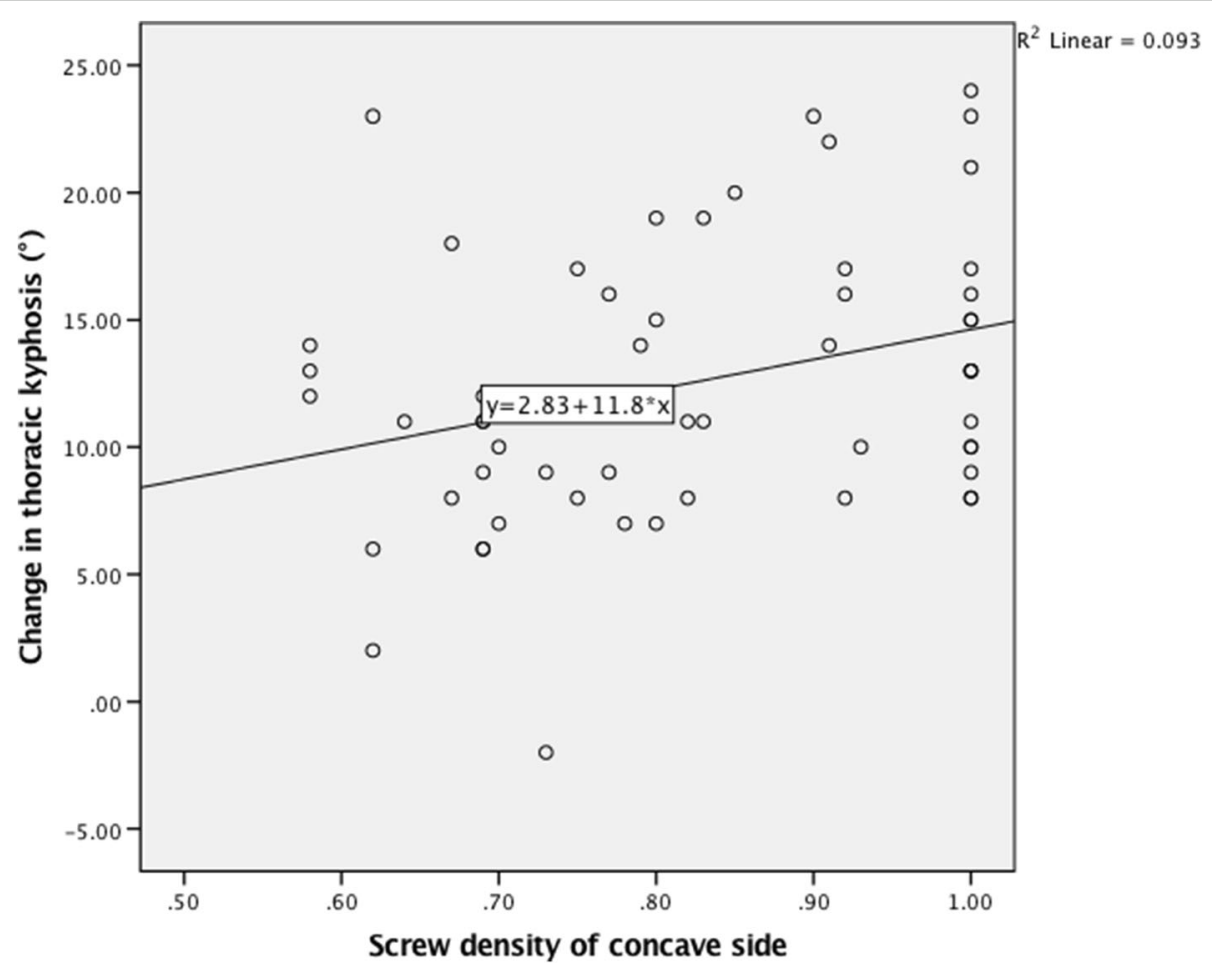

Fig. 3 Correlation between change in thoracic kyphosis and convex side screw density 
Table 1 Correlation analysis between change in thoracic kyphosis and variables

\begin{tabular}{|c|c|c|c|c|c|c|}
\hline \multirow[t]{2}{*}{ Variable } & \multicolumn{3}{|c|}{ Pearson correlation coefficients } & \multicolumn{3}{|c|}{ Spearman correlation coefficients } \\
\hline & $\begin{array}{l}\text { Correlation } \\
\text { coefficient }\end{array}$ & $95 \% \mathrm{Cl}$ & $\begin{array}{l}\text { Statistical } \\
\text { significance }\end{array}$ & $\begin{array}{l}\text { Correlation } \\
\text { coefficient }\end{array}$ & $95 \% \mathrm{Cl}$ & $\begin{array}{l}\text { Statistical } \\
\text { significance }\end{array}$ \\
\hline Age & -0.025 & $(-0.217,0.178)$ & 0.853 & 0.017 & $(-0.220,0.269)$ & 0.899 \\
\hline Flexibility (\%) & 0.357 & $(0.171,0.534)$ & 0.006 & 0.384 & $(0.136,0.578)$ & 0.003 \\
\hline Preoperative MT Cobb angle $\left(^{\circ}\right)$ & -0.138 & $(-0.390,0.136)$ & 0.304 & -0.097 & $(-0.369,0.180)$ & 0.475 \\
\hline Preoperative TK $\left(\mathrm{T} 5-\mathrm{T} 12 ;^{\circ}\right)$ & -0.408 & $(-0.609,-0.186)$ & 0.002 & -0.445 & $(-0.626,-0.214)$ & 0.001 \\
\hline Preoperative LL $\left(\mathrm{L} 1-\mathrm{S} 1 ;^{\circ}\right)$ & 0.148 & $(-0.152,0.459)$ & 0.272 & 0.237 & $(-0.022,0.476)$ & 0.076 \\
\hline Fused levels & 0.010 & $(-0.207,0.220)$ & 0.941 & 0.002 & $(-0.254,0.267)$ & 0.987 \\
\hline Screw density of concave side & 0.306 & $(0.052,0.502)$ & 0.021 & 0.290 & $(0.016,0.513)$ & 0.029 \\
\hline Screw density of convex side & 0.061 & $(-0.222,0.329)$ & 0.655 & 0.063 & $(-0.205,0.318)$ & 0.643 \\
\hline Total screw density & 0.206 & $(-0.069,0.427)$ & 0.123 & 0.213 & $(-0.054,0.441)$ & 0.112 \\
\hline
\end{tabular}

MT indicates main thoracic; TK thoracic kyphosis, LL lumbar lordosis

restoration (postoperative $\mathrm{TK} \geq 20^{\circ}$ ). A positive correlation was found between change in TK and flexibility of MT curve, and in the subgroup analysis, poor flexibility of MT curve was found in the postoperative TK $<20^{\circ}$ group, which suggested that TK restoration was more difficult for patients with a poor flexibility. Interestingly, that was, in our series, if more MT curve correction was achieved, less restoration of TK occurred. It was suggested that excessive correction of the coronal plane was at the expense of sagittal contour. Quan et al. firstly reported that postoperative TK change was negatively correlated with magnitude of coronal Cobb angle correction $(P=0.002)$, and the mechanism was unclear [32]. To our limited knowledge, this might be due to the distraction manipulation of the concave rod, which was aimed at a better coronal correction, unexpectedly consumed the bended rod contour, and further biomechanics study is needed.
The most commonly studied factors influencing TK restoration include the implant rod stiffness, $[17,33] \mathrm{im}$ plant rod curvature, $[19,34]$ anterior endoscopic release, [22] and simultaneous double-rod rotation technique $[23,35,36]$. As regard to implant rod stiffness, lower incidence rate of $\mathrm{CoCr} \operatorname{rod}(P=0.029)$ were found in the postoperative $\mathrm{TK}<20^{\circ}$ group in our study. A biomechanical study reported that the correctional force produced by the $\mathrm{Ti} 30$-degree pre-bend rod was approximately $67 \%$ that of a $\mathrm{CoCr}$ rod [37]. Similar studies also supported using $\mathrm{CoCr}$ rod in hypokyphotic AIS patients $[38,39]$. However, no significant difference was found in rod diameter $(5.5 \mathrm{~mm} / 6.0 \mathrm{~mm})$ in the subgroup analysis, the relatively small sample size and short follow-up time might the two reasons, and a longer follow-up study should be performed to assess the maintenance of TK restoration. In addition, removing the posterior elements (Ponte osteotomy or facetectomy) might increase flexibility and allow the posterior column to lengthen [40].

Table 2 Subgroup comparison of clinical parameters

\begin{tabular}{|c|c|c|c|}
\hline Variable & $\begin{array}{l}\text { Group } 1 \\
\text { (Postop TK } \geq 20^{\circ} \text { ) }\end{array}$ & $\begin{array}{l}\text { Group } 2 \\
\text { (Postop } T K<20^{\circ} \text { ) }\end{array}$ & $P$ value \\
\hline Gender (female/male) & $13 / 4$ & $32 / 8$ & 0.765 \\
\hline Age at surgery (year) & $14.41 \pm 1.50$ & $14.38 \pm 1.96$ & 0.945 \\
\hline Rod diameter $(5.5 \mathrm{~mm} / 6.0 \mathrm{~mm})$ & $4 / 13$ & $15 / 25$ & 0.306 \\
\hline Rod material (Ti/CoCr) & $7 / 10$ & $28 / 12$ & 0.041 \\
\hline Fused levels & $12.18 \pm 1.33$ & $11.38 \pm 1.69$ & 0.088 \\
\hline Total screw number & $18.06 \pm 3.82$ & $16.43 \pm 3.53$ & 0.124 \\
\hline Screw number of concave side & $10.35 \pm 1.73$ & $9.15 \pm 1.90$ & 0.029 \\
\hline Screw number of convex side & $7.71 \pm 2.37$ & $7.28 \pm 2.03$ & 0.488 \\
\hline Total screw density & $1.49 \pm 0.28$ & $1.45 \pm 0.25$ & 0.637 \\
\hline Screw density of concave side & $0.85 \pm 0.13$ & $0.81 \pm 0.14$ & 0.279 \\
\hline Screw density of convex side & $0.63 \pm 0.18$ & $0.64 \pm 0.15$ & 0.854 \\
\hline
\end{tabular}

Values are mean \pm standard deviation, number of participants, or as otherwise indicated

$\mathrm{Ti}$ indicates titanium, $\mathrm{CoCr}$ cobalt chromium 
Table 3 Subgroup comparison of radiographic parameters

\begin{tabular}{|c|c|c|c|}
\hline Variable & $\begin{array}{l}\text { Group } 1 \\
\text { (Postop TK } \geq 20^{\circ} \text { ) }\end{array}$ & $\begin{array}{l}\text { Group } 2 \\
\text { (Postop TK<20 ) }\end{array}$ & $P$ value \\
\hline Lenke classification (1/2/3) & $10 / 4 / 3$ & $18 / 12 / 10$ & - \\
\hline Riser sign & $2.47 \pm 1.23$ & $2.90 \pm 1.46$ & 0.294 \\
\hline Apical vertebra rotation (Nash-Moe) & $1.71 \pm 0.47$ & $1.60 \pm 0.67$ & 0.558 \\
\hline Convex-Bending Cobb angle $\left(^{\circ}\right)$ & $27.12 \pm 5.48$ & $31.53 \pm 7.33$ & 0.804 \\
\hline Flexibility (\%) & $51 \pm 4$ & $42 \pm 8$ & $<0.0001$ \\
\hline Preoperative MT Cobb angle $\left({ }^{\circ}\right)$ & $55.82 \pm 10.48$ & $54.98 \pm 12.23$ & 0.804 \\
\hline Postoperative MT Cobb angle $\left(^{\circ}\right)$ & $17.88 \pm 7.53$ & $14.83 \pm 7.59$ & 0.169 \\
\hline Change in MT Cobb angle $\left(^{\circ}\right)$ & $37.94 \pm 9.65$ & $40.15 \pm 8.28$ & 0.384 \\
\hline MT curve correction (\%) & $68 \pm 13$ & $74 \pm 10$ & 0.079 \\
\hline Preoperative TK (T5-T12; $\left.{ }^{\circ}\right)$ & $5.18 \pm 3.28$ & $4.58 \pm 3.54$ & 0.552 \\
\hline Postoperative TK $\left(\mathrm{T}_{5}-\mathrm{T} 12{ }^{\circ}{ }^{\circ}\right)$ & $23.41 \pm 3.20$ & $14.70 \pm 3.22$ & $<0.0001$ \\
\hline Change in TK (T5-T12; $\left.{ }^{\circ}\right)$ & $18.24 \pm 4.05$ & $10.13 \pm 3.99$ & $<0.0001$ \\
\hline Preoperative LL (L1-S1; $\left.{ }^{\circ}\right)$ & $-45.76 \pm 9.68$ & $-48.80 \pm 9.33$ & 0.271 \\
\hline Postoperative LL (L1-S1; $\left.{ }^{\circ}\right)$ & $-50.82 \pm 8.75$ & $-51.35 \pm 8.49$ & 0.833 \\
\hline Change in $L L\left(L 1-S 1 ;^{\circ}\right)$ & $-5.06 \pm 13.51$ & $-2.55 \pm 10.35$ & 0.449 \\
\hline
\end{tabular}

Values are mean \pm standard deviation, number of participants, or as otherwise indicated MT indicates main thoracic; TK thoracic kyphosis, LL lumbar lordosis

Shah et al. found a significant restoration in TK from $8.1^{\circ}$ to $18.3^{\circ}(P<0.001)$ in hypokyphotic curves treated with Ponte osteotomy [41]. Sudo et al. reported a significant correlation between change in TK and number of facetectomy level $(r=0.492, P=0.002)$ [42]. Therefore, $\mathrm{CoCr}$ rod and posterior column release should be taken into consideration for hypokyphotic AIS.

Few studies have evaluated the correlation between implant density and sagittal correction, and conclusions were controversial. Liu et al. compared the effects of high versus low implant density on sagittal plane correction, and greater TK restoration was found in AIS patients with high screw density on the concave side $(P<0.05)$ [17]. Similarity, Sudo et al. retrospectively reviewed Lenke type 1 AIS patients with preoperative $\mathrm{TK}<15^{\circ}$, and change in TK was significantly correlated with concave side screw density $(r=0.351)$ but not with convex side screw density $(r=0.144)$ [18]. Contrarily, Larson et al. retrospectively reviewed a multicenter database and found decreased TK (T2-T12) with an increased implant density for Lenke type $1(n=375)$ and type $2(n=245)$ curves [16]. While, the included patients were not classified into hypokyphosis, normal kyphosis, and hyperkyphosis based on TK. The difference between the average angles of TK was probably the primary cause for differing conclusions.

Through this study, we found that concave side screw density was positively correlated with TK restoration in thoracic AIS patients with hypokyphosis, In addition, smaller screw number of concave side were found in the postoperative $\mathrm{TK}<20^{\circ}$ group. Which suggested that higher concave side screw density provided a beneficial effect on TK restoration in hypokyphotic AIS. A possible explanation is that the concave side rod provides a stronger corrective force on the sagittal plane with more pedicle screws. Cidambi et al. reported that the resulting deformations were likely to be associated with substantial in vivo deforming forces, particularly for concave rods [20]. Similar conclusion were demonstrated by Salmingo et al. [19]. In addition, Abe et al. analyzed scoliosis corrective forces and pull out forces based on finite element analysis and found that the corrective force was roughly four times greater in the concave side than in the convex side [43]. Implanted pedicle screws were under the effect of two forces that included the corrective force exerted from the stiffness of the rod and the resistant force from the deformed spine. It was possible that more pedicle screws were inserted at the concave side rod, providing a stronger pullout force. According to reciprocity of force, the stronger pullout force would convert into a corrective force and could be evenly applied on the hypokyphosis spine. Then, the hypokyphosis spine would be restored and follow the curvature of the concave side rod.

An important limitation of the study was that the analysis of rod curvature prior to implantation was limited due to the retrospective study. In addition, the relatively small sample size and short follow-up time were underpowered to find more significant difference, and larger-scale and longer follow-up research should be performed. 


\section{Conclusions}

TK restoration remains a challenge for AIS patients with hypokyphosis, especially for poor flexibility ones. Except for thicker and cobalt chromium rods, screw density of concave side might be another positive predictor of restoring normal kyphosis, which provides a stronger corrective force on the sagittal plane with more pedicle screws.

\section{Abbreviations}

AIS: Adolescent idiopathic scoliosis; MT: Main thoracic; TK: Thoracic kyphosis

\section{Acknowledgements}

The authors would like to express their gratitude to Miss Kun Wang, from Tongji Hospital of Tongji medical college, for her comments and advice on statistical analysis in this study. All the authors were directly involved in the whole process; therefore, it is disclosed that all the authors contributed equally towards the research.

\section{Funding}

This research was funded by Henan provincial department of science and technology (Grant No. 142300410379 and 152102410062).

\section{Availability of data and materials}

This article is a clinical retrospective study, and all relevant data are within the paper. The raw datasets used and/or analyzed during this study are available from the corresponding author on reasonable request.

\section{Authors' contributions}

$\mathrm{ML}$ and $\mathrm{LX}$ contributed to the conception. ML, WGW, and PL contributed to the designs and the draft of the work and revised it critically for important intellectual content. NL, MKS and GZX did the acquisition and analysis of the data. ML and $\mathrm{HHJ}$ revised this study critically for important intellectual content. LX and ML approved the version to be published. All authors read and approved the final manuscript.

\section{Ethics approval and consent to participate}

This retrospective study has been approved by the Ethics Committee of the First Affiliated Hospital of Zhengzhou University. The consent has been received from the parents of the from all participants in this study.

\section{Consent for publication}

Not applicable.

\section{Competing interests}

The authors declare that they have no competing interests.

\section{Publisher's Note}

Springer Nature remains neutral with regard to jurisdictional claims in published maps and institutional affiliations.

\section{Author details \\ ${ }^{1}$ Institute of Spinal Deformity, the First Affiliated Hospital of Zhengzhou University, Zhengzhou, Henan 450052, People's Republic of China. ${ }^{2}$ Department of Orthopaedic Surgery, Central Hospital of Wuhan, Tongji Medical College, Huazhong University of Science \& Technology, Wuhan, People's Republic of China.}

Received: 11 June 2017 Accepted: 28 November 2017

Published online: 13 December 2017

\section{References}

1. Weinstein SL, Dolan LA, Cheng JC, Danielsson A, Morcuende JA. Adolescent idiopathic scoliosis. Lancet (London, England). 2008;371(9623):1527-37.

2. Newton PO, Yaszay B, Upasani W, Pawelek JB, Bastrom TP, Lenke LG, Lowe T, Crawford A, Betz R, Lonner B. Preservation of thoracic kyphosis is critical to maintain lumbar lordosis in the surgical treatment of adolescent idiopathic scoliosis. Spine. 2010;35(14):1365-70.
3. Lonner BS, Lazar-Antman MA, Sponseller PD, Shah SA, Newton PO, Betz R, Shufflebarger HS. Multivariate analysis of factors associated with kyphosis maintenance in adolescent idiopathic scoliosis. Spine. 2012;37(15):1297-302.

4. Cao Y, Xiong W, Li F. Pedicle screw versus hybrid construct instrumentation in adolescent idiopathic scoliosis: meta-analysis of thoracic kyphosis. Spine. 2014:39(13):E800-10.

5. Lenke LG, Betz RR, Harms J, Bridwell KH, Clements DH, Lowe TG, Blanke K. Adolescent idiopathic scoliosis: a new classification to determine extent of spinal arthrodesis. J Bone Joint Surg Am. 2001;83-a(8):1169-81.

6. Edgar M. A new classification of adolescent idiopathic scoliosis. Lancet (London, England). 2002;360(9329):270-1.

7. Winter RB, Lovell WW, Moe JH. Excessive thoracic lordosis and loss of pulmonary function in patients with idiopathic scoliosis. J Bone Joint Surg Am. 1975;57(7):972-7.

8. Newton PO, Faro FD, Gollogly S, Betz RR, Lenke LG, Lowe TG. Results of preoperative pulmonary function testing of adolescents with idiopathic scoliosis. A study of six hundred and thirty-one patients. J Bone Joint Surg Am. 2005;87(9):1937-46

9. Yaszay B, Bastrom TP, Bartley CE, Parent S, Newton PO. The effects of the three-dimensional deformity of adolescent idiopathic scoliosis on pulmonary function. Eur Spine J. 2016:[Epub ahead of print].

10. Bernstein P, Hentschel S, Platzek I, Huhne S, Ettrich U, Hartmann A, Seifert J. Thoracal flat back is a risk factor for lumbar disc degeneration after scoliosis surgery. Spine J. 2014;14(6):925-32.

11. Roussouly P, Nnadi C. Sagittal plane deformity: an overview of interpretation and management. Eur Spine J. 2010;19(11):1824-36.

12. Khakinahad M, Ameri $\mathrm{E}$, Ghandhari $\mathrm{H}$, Tari H. Preservation of thoracic kyphosis is critical to maintain lumbar lordosis in the surgical treatment of adolescent idiopathic scoliosis. Acta medica Iranica. 2012;50(7):477-81.

13. Clements DH, Betz RR, Newton PO, Rohmiller M, Marks MC, Bastrom T. Correlation of scoliosis curve correction with the number and type of fixation anchors. Spine. 2009:34(20):2147-50.

14. Yang S, Jones-Quaidoo SM, Eager M, Griffin JW, Reddi V, Novicoff W, Shilt J, Bersusky E, Defino $\mathrm{H}$, Ouellet J, et al. Right adolescent idiopathic thoracic curve (Lenke $1 \mathrm{a}$ and $\mathrm{B}$ ): does cost of instrumentation and implant density improve radiographic and cosmetic parameters? Eur Spine J. 2011;20(7):1039-47.

15. Chen J, Yang C, Ran B, Wang Y, Wang C, Zhu X, Bai Y, Li M. Correction of Lenke 5 adolescent idiopathic scoliosis using pedicle screw instrumentation: does implant density influence the correction? Spine. 2013;38(15):E946-51.

16. Larson AN, Polly DW, Jr. Diamond B, Ledonio C, Richards BS, 3rd, Emans JB, Sucato DJ, Johnston CE: Does higher anchor density result in increased curve correction and improved clinical outcomes in adolescent idiopathic scoliosis? Spine 2014, 39(7):571-578.

17. Liu H, Li Z, Li S, Zhang K, Yang H, Wang J, Li X, Zheng Z. Main thoracic curve adolescent idiopathic scoliosis: association of higher rod stiffness and concave-side pedicle screw density with improvement in sagittal thoracic kyphosis restoration. J Neurosurg Spine. 2015;22(3):259-66.

18. Sudo H, Abe Y, Kokabu T, Ito M, Abumi K, Ito YM, Iwasaki N: Correlation analysis between change in thoracic kyphosis and multilevel facetectomy and screw density in main thoracic adolescent idiopathic scoliosis surgery. Spine J. 2016;16(9):1049-54.

19. Salmingo RA, Tadano S, Abe $Y$, Ito M. Influence of implant rod curvature on sagittal correction of scoliosis deformity. Spine J. 2014;14(8):1432-9.

20. Cidambi KR, Glaser DA, Bastrom TP, Nunn TN, Ono T, Newton PO. Postoperative changes in spinal rod contour in adolescent idiopathic scoliosis: an in vivo deformation study. Spine. 2012;37(18):1566-72.

21. Monazzam S, Newton PO, Bastrom TP, Yaszay B. Multicenter comparison of the factors important in restoring thoracic Kyphosis during posterior instrumentation for adolescent idiopathic scoliosis. Spine Deformity. 2013; 1(5):359-64.

22. Ferrero E, Pesenti S, Blondel B, Jouve JL, Mazda K, Iharreborde B. Role of thoracoscopy for the sagittal correction of hypokyphotic adolescent idiopathic scoliosis patients. Eur Spine J. 2014;23(12):2635-42.

23. Sudo H, Ito M, Abe Y, Abumi K, Takahata M, Nagahama K, Hiratsuka S, Kuroki K, Iwasaki N. Surgical treatment of Lenke 1 thoracic adolescent idiopathic scoliosis with maintenance of kyphosis using the simultaneous double-rod rotation technique. Spine. 2014;39(14):1163-9.

24. de Jonge T, Dubousset JF, Illes T. Sagittal plane correction in idiopathic scoliosis. Spine. 2002;27(7):754-60.

25. Potter BK, Lenke LG, Kuklo TR. Prevention and management of iatrogenic flatback deformity. J Bone Joint Surg Am. 2004;86-a(8):1793-808. 
26. Watanabe K, Nakamura T, Iwanami A, Hosogane N, Tsuji T, Ishii K, Nakamura M, Toyama Y, Chiba K, Matsumoto M. Vertebral derotation in adolescent idiopathic scoliosis causes hypokyphosis of the thoracic spine. BMC Musculoskelet Disord. 2012:13:99.

27. Glassman SD, Sucato DJ, Carreon LY, Sanders JO, Vitale MG, Lenke LG. Does thoracic Hypokyphosis matter in Lenke type 1 adolescent idiopathic scoliosis? Spine Deformity. 2013;1(1):40-5.

28. Johnston CE, Richards BS, Sucato DJ, Bridwell KH, Lenke LG, Erickson M. Correlation of preoperative deformity magnitude and pulmonary function tests in adolescent idiopathic scoliosis. Spine. 2011;36(14):1096-102.

29. Helgeson MD, Shah SA, Newton PO, Clements DH 3rd, Betz RR, Marks MC Bastrom T. Evaluation of proximal junctional kyphosis in adolescent idiopathic scoliosis following pedicle screw, hook, or hybrid instrumentation. Spine. 2010;35(2):177-81.

30. Canavese F, Turcot K, De Rosa V, de Coulon G, Kaelin A. Cervical spine sagittal alignment variations following posterior spinal fusion and instrumentation for adolescent idiopathic scoliosis. Eur Spine J. 2011;20(7):1141-8.

31. Matsumoto H, Colacchio ND, Schwab FJ, Lafage V, Roye DP, Vitale MG. Flatback revisited: reciprocal loss of lumbar Lordosis following selective thoracic fusion in the setting of adolescent idiopathic scoliosis. Spine Deformity. 2015;3(4):345-51.

32. Quan GM, Gibson MJ. Correction of main thoracic adolescent idiopathic scoliosis using pedicle screw instrumentation: does higher implant density improve correction? Spine. 2010;35(5):562-7.

33. Fletcher ND, Hopkins J, McClung A, Browne R, Sucato DJ. Residual thoracic hypokyphosis after posterior spinal fusion and instrumentation in adolescent idiopathic scoliosis: risk factors and clinical ramifications. Spine. 2012;37(3):200-6.

34. Salmingo RA, Tadano S, Fujisaki K, Abe Y, Ito M. Relationship of forces acting on implant rods and degree of scoliosis correction. Clin Biomech (Bristol, Avon). 2013;28(2):122-8.

35. Clement JL, Chau E, Geoffray A, Suisse G. Restoration of thoracic kyphosis by simultaneous translation on two rods for adolescent idiopathic scoliosis. Eur Spine J. 2014;23(Suppl 4):S438-45.

36. Kokabu T, Sudo H, Abe Y, Ito M, Ito YM, Iwasaki N. Effects of multilevel Facetectomy and screw density on postoperative changes in spinal rod contour in thoracic adolescent idiopathic scoliosis surgery. PLoS One. 2016; 11(8):e0161906.

37. Serhan $H$, Mhatre $D$, Newton P, Giorgio P, Sturm P. Would CoCr rods provide better correctional forces than stainless steel or titanium for rigid scoliosis curves? J Spinal Disord Tech. 2013;26(2):E70-4.

38. Lamerain M, Bachy M, Delpont M, Kabbaj R, Mary P, Vialle R. CoCr rods provide better frontal correction of adolescent idiopathic scoliosis treated by all-pedicle screw fixation. Eur Spine J. 2014;23(6):1190-6.

39. Angelliaume A, Ferrero E, Mazda K, Le Hanneur M, Accabled F, de Gauzy JS, Iharreborde B. Titanium vs cobalt chromium: what is the best rod material to enhance adolescent idiopathic scoliosis correction with sublaminar bands? Eur Spine J. 2017:26(6):1732-8.

40. Takahashi J, Ikegami S, Kuraishi S, Shimizu M, Futatsugi T, Kato H. Skip pedicle screw fixation combined with Ponte osteotomy for adolescent idiopathic scoliosis. Eur Spine J. 2014;23(12):2689-95.

41. Shah SA, Dhawale AA, Oda JE, Yorgova P, Neiss Gl, Holmes L Jr, Gabos PG. Ponte Osteotomies with pedicle screw instrumentation in the treatment of adolescent idiopathic scoliosis. Spine deformity. 2013;1(3):196-204.

42. Sudo H, Abe Y, Kokabu T, Ito M, Abumi K, Ito YM, Iwasaki N. Correlation analysis between change in thoracic kyphosis and multilevel facetectomy and screw density in main thoracic adolescent idiopathic scoliosis surgery. Spine J. 2016;16(9):1049-54.

43. Abe $Y$, Ito M, Abumi K, Sudo H, Salmingo R, Tadano S. Scoliosis corrective force estimation from the implanted rod deformation using 3D-FEM analysis. Scoliosis. 2015;10(S2):1-6.

\section{Submit your next manuscript to BioMed Central and we will help you at every step:}

- We accept pre-submission inquiries

- Our selector tool helps you to find the most relevant journal

- We provide round the clock customer support

- Convenient online submission

- Thorough peer review

- Inclusion in PubMed and all major indexing services

- Maximum visibility for your research

Submit your manuscript at www.biomedcentral.com/submit
C Biomed Central 